\title{
Objective short sleep duration is associated with the activity of the hypothalamic-pituitary-adrenal axis in insomnia
}

Insônia, com tempo de sono curto, medido objetivamente, esta associada a atividade do eixo hipotálamo-hipófise-adrenal

Carolina D’Aurea, Dalva Poyares, Ronaldo D. Piovezan, Giselle Soares Passos, Sergio Tufik, Marco Tulio de Mello

\begin{abstract}
Objective: To evaluate the association between objective short sleep duration in patients with insomnia and changes in blood parameters related to hypothalamic-pituitary-adrenal (HPA) axis activity. Method: A cross-sectional pilot study was conducted in 30 middle-aged adults with chronic insomnia who were divided into 2 groups according to polysomnography (PSG) total sleep time (TST) (TST $>5$ h and $<5$ h). All patients underwent subjective analysis of sleep quality, anthropometric measurements, PSG, and determination off asting blood parameters. Results: The results revealed lower sleep efficiency and higher sleep latency for those with a TST $<5$ h. The subjective sleep quality was worse in the TST $<5$ h. Significantly, higher glucose and cortisol levels were observed with a TST < 5h. Glucose, cortisol and ACTH levels were inversely correlated with the PSG total sleep time. Conclusion: Patients with insomnia with objective short sleep duration had HPA-associated endocrine and metabolic imbalances chronically linked to increases in cardiovascular risk observed with this more severe insomnia phenotype.
\end{abstract}

Keywords: insomnia disorder, objective short sleep duration, hypothalamic-pituitary-adrenal axis.

\section{RESUMO}

Objetivo: Avaliar a associação entre insônia com tempo de sono curto e alterações sanguíneas relacionados com a atividade do eixo hipotálamo-hipófise-adrenal (HPA). Método: Estudo piloto transversal, com 30 adultos de meia-idade, distribuídos em 2 grupos de acordo com o tempo total de sono (TTS) pela polisonografia (PSG) (TTS $>5 \mathrm{~h}$ e $<5 \mathrm{~h}$ ). Os pacientes foram submetidos a análise subjetiva da qualidade do sono, medidas antropométricas, PSG e parâmetros sanguíneos em jejum. Resultados: Revelaram baixa eficiência do sono e maior latência do sono para aqueles com TTS < 5h. A qualidade subjetiva do sono foi pior no TTS < 5h. Significativamente, os níveis de glicose e cortisol mais elevados foram observados no grupo com TTS < 5h. Os níveis de glicose, cortisol e ACTH foram inversamente correlacionados com o TTS da PSG. Conclusão: Pacientes com insônia com tempo de sono curto apresentaram desequilíbrios endócrinos e metabólicos associados a atividade do eixo HPA, correlacionados ao aumento do risco cardiovascular observado neste fenótipo mais grave de insônia.

Palavras-chave: transtornos de insônia, curta duração objetiva de sono, eixo hipotálamo-pituitária-adrenal.

Difficulties in initiating or maintaining sleep and associated impairment in daytime activities for a duration of at least six months are the defining features of chronic insomnia, which affects $10 \%$ of the population ${ }^{1,2,3}$. Although insomnia syndrome involves subjective complaints, insomnia with objective short sleep duration [total sleep time $(\mathrm{TST})<5 \mathrm{~h}$, as assessed by polysomnography (PSG)] is possibly a more severe biological phenotype of this sleep disorder and is a predictor for the persistence of this condition ${ }^{4}$.
Insomnia disorder with objective short sleep durationis associated with increasing incidence of hypertension and negatively impacts the variability of blood pressure and heart rate, which has been associated with increased cardiovascular mortality ${ }^{5,67}$. A cross-sectional analysis revealed that insomnia with objective short sleep duration is associated with an increased risk of diabetes ${ }^{8}$. Hypothalamic-pituitary-adrenal (HPA) axis activity plays a role in hypertension and diabetes development ${ }^{9,10}$. However, data suggesting that HPA hormone levels are higher in insomnia are still inconclusive $\mathrm{e}^{11,12,13}$.

\footnotetext{
Universidade Federal de São Paulo, Departamento de Psicobiologia, Divisão de Medicina do Sono, São Paulo SP, Brazil. Correspondence: Carolina Vicaria R. D’Aurea; Rua Napoleão de Barros, 925/2ªndar; 04024-002 São Paulo SP, Brasil; E-mail: fisiocarol@uol.com.br Conflict of interest: There is no conflict of interest to declare.

Support: Associação Fundo de Incentivo a Pesquisa (AFIP), Fundação de Amparo a Pesquisa do estado de São Paulo (FAPESP) and Centro de Estudos em Psicobiologia do Exercício (CEPE). Dalva Poyares and Sergio Tufik are recipients of Conselho Nacional de Desenvolvimento Científico e Tecnológico (CNPQ) grants. Received 05 November 2014; Received in final form 21 January 2015; Accepted 13 February 2015.
} 
Studies targeting more severe insomnia phenotypes with respect to HPA activity may clarify this possible association. This pilot study aimed to evaluate the association between fasting blood parameters related to HPA activity and short sleep time as assessed by PSG in patients with chronic insomnia disorder.

\section{METHOD}

This cross-sectional pilot study was conducted at the Sleep Institute of Sao Paulo and at the Federal University of Sao Paulo, Brazil. An initial pre-interview was conducted via telephone, and the first 100 volunteers with insomnia complaints were pre-screened. Of the 100 volunteers, we evaluated 60 patients. Thirty patients of both genders fulfilled the inclusion criteria and were diagnosed with chronic insomnia, adapted from DSM-V criteria ${ }^{14}$. Each patient underwent an interview so that the protocol procedures could be explained and signed a consent form to participate in the study. Anonymity was guaranteed during all data collection and reporting. The study protocol was approved by the Federal University of Sao Paulo Ethics Committee, Sao Paulo, Brazil.

The inclusion criteria were an age between 30 and 55 years and diagnosis of chronic insomnia exceeding 6 months. The exclusion criteria were use of psychoactive drugs, history of relevant neurological and psychiatric or medical conditions, shift work, presence of other sleep disorders, significant abnormalities in laboratory tests, apnea/hypopnea index (AHI) $>5$, use of CPAP for sleep apnea, periodic leg movement in$\operatorname{dex}(\mathrm{PLMI})>15$, and abnormalities in cardiac tests (ECG at rest and with exercise).

We defined TST as two consecutive PSG nights. Seven patients who slept less than 5 hours in each of the 2 consecutive PSG nights were allocated into the "TST $<5$ h" group (full PSG sleep time $<5$ hours). Twenty-three primary insomnia patients who slept more than 5 hours in the two PSG nights were included in the "TST > 5h" group ( full PSG sleep time $>5$ hours). Subjective sleep quality assessment was performed using the Pittsburgh Sleep Quality Index (PSQI) ${ }^{15}$.

Two consecutive laboratory-based PSGs were recorded with a digital system device (S7000; Embla Systems, Thornton, CO) during the participants' habitual sleep time. Standard montage and criteria for scoring sleep stages were used $^{16}$. Arousals, leg movements and respiratory events were scored according to the guidelines provided by the American Academy of Sleep Medicine ${ }^{17}$.

Fasting metabolic laboratory parameters were measured, including glucose, cortisol, insulin, adrenocorticotropic hormone (ACTH) and growth hormone (GH). Blood samples were collected when the patients awakened. HOMA-IR was calculated using fasting glucose and insulin parameters.

The body composition included lean and fat mass assessments obtained via plethysmography, which involves the use of an electronic balance, a plethysmograph, a cylinder for calibration, and dedicated software. The density of the whole body was obtained by dividing the body weight by the body volume.

Descriptive analyses were applied to the subject characteristics and the collected data. The differences between the groups were compared using the Mann-Whitney U test for continuous variables and the chi-square test for frequencies. $\mathrm{P}$ values of $\leq .05$ were considered significant. The statistical analyses were performed using the Statistical Package for Social Sciences (SPSS) version17.0 for Windows (SPSS Inc., Chicago, Illinois). The Spearman's rank correlation coefficients were obtainedby considering the PSG total sleep time, socio-demographic variables and blood parameters.

\section{RESULTS}

No significant differences were found with respect to socio-demographic variables between the two groups (TST $>5 \mathrm{~h}$ and TST $<5 \mathrm{~h}$ ). The majority of both groups are women which coincide with the prevalence of insomnia that is more common in females. The body mass index (BMI) and body composition were also similar in both groups. Comparisons of the PSG variables showed lower sleep efficiency and higher sleep onset latency for the TST $<5 \mathrm{~h}$ group ( $p<0.01$ and $p=0.03$, respectively).The demographic and PSG results are detailed in Table 1. The PSQI score was significantly higher among the insomnia patients who slept less than 5 hours, indicating worse sleep quality in this group $(10.8 \pm 2.2$ vs. $14.1 \pm 1.0, \mathrm{p}<0.01)$.

With regard to laboratory metabolic variables, patients who slept less than 5 hours had higher fasting glucose and cortisol levels than those who slept more than 5 hours ( $p=0.01$ and $p=0.02$, respectively) (values are displayed in Table 2). No differences were found for the other variables. Fasting glucose, ACTH and cortisol levels demonstrated inverse correlation with the total sleep time $(r=-0.28, p=0.16$; $r=-0.38, p=0.03 ; r=-0.47, p<0.01$, respectively).

\section{DISCUSSION}

We found that an objective sleep duration less than $5 \mathrm{~h}$ was associated with increased glucose and cortisol levels and a decreased subjective sleep quality in chronic insomnia patients. Total sleep time was inversely correlated with glucose, cortisol and ACTH levels. Shorter sleep was not associated with differences in BMI and body composition in our sample. We excluded cases of sleep disorders related to increased HPA activity, such as sleep-disordered breathing.

To the best of our knowledge, this study was the first to analyze blood metabolic parameters related to HPA axis activity of non-diabetic middle-aged adults with chronic insomnia 
Table 1. Demographic and polysomnography (PSG) variables.

\begin{tabular}{|c|c|c|c|}
\hline Characteristics & $\begin{array}{c}\text { TST }>5 \text { hours } \\
(n=23)\end{array}$ & $\begin{array}{c}\text { TST }<5 \text { hours } \\
\quad(n=7)\end{array}$ & $p$-value \\
\hline Gender (M/F) & $3 / 20$ & $2 / 5$ & \\
\hline Age (years) & $44.90 \pm 8.8$ & $43.10 \pm 9.1$ & 0.74 \\
\hline $\mathrm{BMI}\left(\mathrm{kg} / \mathrm{m}^{2}\right)$ & $24.50 \pm 4.7$ & $24.30 \pm 2.80$ & 0.78 \\
\hline$\%$ fat mass & $30.60 \pm 9.6$ & $32.50 \pm 11.90$ & 0.58 \\
\hline$\%$ lean mass & $69.40 \pm 9.8$ & $67.40 \pm 11.90$ & 0.62 \\
\hline Insomnia duration (months) & $9.90 \pm 7.0$ & $13.90 \pm 10.60$ & 0.47 \\
\hline PSG N1 (\%) & $3.51 \pm 1.89$ & $4.24 \pm 2.52$ & 0.41 \\
\hline PSG N2 (\%) & $55.73 \pm 8.35$ & $60.28 \pm 2.99$ & 0.17 \\
\hline PSG N3 (\%) & $19.60 \pm 6.30$ & $19.10 \pm 4.80$ & 0.84 \\
\hline PSG REM (\%) & $20.79 \pm 6.87$ & $16.30 \pm 3.60$ & 0.11 \\
\hline PSG SOL (min) & $12.17 \pm 10.45$ & $24.25 \pm 11.15^{\star}$ & 0.03 \\
\hline PSG REM Lat (min) & $92.9 \pm 44.00$ & $130.70 \pm 69.90$ & 0.24 \\
\hline PSG TST (min) & $355.31 \pm 36.17$ & $256.21 \pm 49.83^{*}$ & $<0.01$ \\
\hline PSG SE (\%) & $84.30 \pm 7.90$ & $67.00 \pm 15.30 *$ & $<0.01$ \\
\hline PSG WASO (min) & $52.60 \pm 28.80$ & $90.10 \pm 18.10$ & 0.41 \\
\hline $\mathrm{Al}$ & $45.19 \pm 52.38$ & $15.35 \pm 14.42$ & 0.15 \\
\hline $\mathrm{AHI}$ & $7.27 \pm 7.41$ & $9.74 \pm 11.50$ & 0.50 \\
\hline PLM & $1.99 \pm 4.31$ & $0.00 \pm 0.00$ & 0.23 \\
\hline $\mathrm{SaO} 2(\%)$ & $95.82 \pm 1.31$ & $95.40 \pm 2.09$ & 0.64 \\
\hline \multicolumn{4}{|c|}{$\begin{array}{l}{ }^{*} \mathrm{p}<0.05, \text { Mann-Whitney U test. BMI: body mass index; PSG N1 (\%): } \\
\text { percentage of stage N1; PSG N2 (\%): percentage of stage N2; PSG N3 (\%): } \\
\text { percentage of slow wave sleep (stage N3); PSG REM (\%): percentage of REM } \\
\text { stage; PSG SOL (min): sleep onset latenc; PSG REM Lat (min): REM latency; } \\
\text { PSG TST (min): total sleep time; PSG SE (\%): sleep efficiency; PSG WASO (min): } \\
\text { time to wake after sleep onset; Al: arousal index (per hour); AHI: apnea and } \\
\text { hypopnea index (per hour); PLM: periodic leg movement (per hour); SaO2 (\%): } \\
\text { mean oxygen saturation during sleep. }\end{array}$} \\
\hline
\end{tabular}

disorder with objective short sleep duration as measured by 2 consecutive PSGs. The HPA axis plays a role in the glucose metabolism impairment observed in insomnia as determined by objective and subjective criteria ${ }^{18}$. Objective short sleep duration is associated with physiological hyper-arousal in insomnia patients ${ }^{19,20}$. Chronic stress system activity is related to increased cortisol levels ${ }^{21}$. Persistent sleep restriction may lead to insulin resistance and an increased risk of diabetes over time $e^{22,23}$. Our findings confirm this hypothesis in part. Insulin and HOMA-IR did not differ between the groups.

Previous studies have examined the concept of objective short sleep duration based on only one PSG night ${ }^{24}$. Although we have used data from more than one PSG night to classify short sleep duration, we still acknowledge that this data may not fully represent the sleep habits of subjects. The small sample size, mostly in the TST $<5$ h group, the absence of a group of "good sleepers", and the cross-sectional design limit the magnitude of our conclusions and causality inferences in the directions of the associations. As an example, the ACTH
Table 2. Blood parameters.

\begin{tabular}{lccc}
\hline Variables & $\begin{array}{c}\text { TST }>5 \text { hours } \\
(n=23)\end{array}$ & $\begin{array}{c}\text { TST }<5 \text { hours } \\
(n=7)\end{array}$ & p-value \\
\hline Fasting glucose $(\mathrm{mg} / \mathrm{dL})$ & $95.21 \pm 6.80$ & $102.28 \pm 4.50 *$ & 0.01 \\
Cortisol $(\mu \mathrm{g} / \mathrm{dL})$ & $12.75 \pm 4.70$ & $17.20 \pm 2.80 *$ & 0.02 \\
Insulin $(\mu \mathrm{lU} / \mathrm{mL})$ & $7.41 \pm 4.10$ & $9.07 \pm 6.30$ & 0.73 \\
HOMA IR & $1.78 \pm 1.07$ & $2.31 \pm 1.68$ & 0.32 \\
ACTH $(\mathrm{pg} / \mathrm{mL})$ & $21.63 \pm 21.20$ & $73.21 \pm 14.30$ & 0.32 \\
GH $(\mathrm{ng} / \mathrm{mL})$ & $10.70 \pm 28.60$ & $16.37 \pm 37.40$ & 0.67 \\
\hline${ }^{*} \mathrm{p}<0.05, \mathrm{Mann}-$ Whitney U test. & &
\end{tabular}

and insulin measurements presented a non-significant increasing trend in the insomnia group with short sleep duration. This result may be due to the low number of participants in this pilot study, which possibly underpowered the magnitude of the differences found between groups. More precise measurements of glucose metabolism, insulin sensitivity and HPA axis feedback control than those used in this study are also necessary to confirm our findings.

Furthermore, treating TST as a continuous variable for a secondary analysis demonstrated that fasting glucose, cortisol and ACTH levels displayed a fair inverse correlation with TST. These results favor the hypothesis that decreased sleep duration is relatedto changes in the HPA axis. Once chronic, this neuroendocrine pattern is a potential risk factor for diabetes, obesity and cardiovascular disease $\mathrm{e}^{25}$.

Keckels et al. found no association between insomnia and impaired glucose metabolism. However, the mean TST in the insomnia group was greater than $5 \mathrm{~h}$, and no sub-group analysis was performed to compare TST below and above $5 h^{26}$. In fact, an objective sleep duration of less than $5 \mathrm{~h}$ is necessary to increase the risk of diabetes ${ }^{8,27}$. The severity of sleep disturbance is a key component in metabolic control, as only severe sleep apnea is clearly related to the risk of impaired glucose metabolism ${ }^{28}$.

In conclusion, objective sleep duration of less than $5 \mathrm{~h}$ in chronic insomnia disorder patients was associated with hormonal and metabolic measurements that indicated changes in HPA axis activity. Because insomnia is a chronic condition and our sample was composed of middle-aged adults, long-term preventive strategies targeting the morbidity and mortality related to poor sleep and its potential metabolic consequences may be effective. Insomnia disorder is a heterogeneous condition, and specific subtypes, such as insomnia with objective short sleep duration, require further investigation with respect to potential clinical outcomes and effective interventions.

\section{References}

1. Ohayon MM, Riemann D, Morin C, Reynolds CF 3rd. Hierarchy of insomnia criteria based on daytime consequences. Sleep Med. 2012;13(1):52-7. http://dx.doi.org/10.1016/j.sleep.2011.06.010
2. National Institutes of Health. National Institutes of Health State of the Science Conference statement on Manifestations and Management of Chronic Insomnia in Adults, 13-15 June, 2005. Sleep. 2005;28(9):1049-57. 
3. Morin CM, Benca R. Chronic insomnia. Lancet. 2012;379(9821):1129-41. http://dx.doi.org/10.1016/S0140-6736(11)60750-2

4. Fernandez-Mendoza J, Calhoun S, Bixler EO, Pejovic S, Karataraki M, Liao Dl. Insomnia with objective short sleep duration is associated with deficits in neuropsychological performance: a general population study. Sleep. 2010;33(4):459-65.

5. Fernandez-Mendoza J, Vgontzas AN, Liao D, Shaffer ML, Vela-Bueno A, Basta M et al. Insomnia with objective short sleep duration and incident hypertension: the Penn State Cohort. Hypertension. 2012;60(4):929-35. http://dx.doi.org/10.1161/HYPERTENSIONAHA.112.193268

6. Vgontzas AN; Liao D; Bixler EO; Chrousos GP; Vela-Bueno A. Insomnia with objective short sleep duration is associated with a high risk for hypertension. Sleep. 2009;32(4):491-7.

7. Johansson JK, Kronholm E, Jula AM. Variability in home-measured blood pressure and heart rate: associations with self-reported insomnia and sleep duration. J Hypertens. 2011;29(10):1897-905. http://dx.doi.org/10.1097/HJH.0b013e32834abccd

8. Vgontzas AN, Liao D, Pejovic S, Calhoun S, Karataraki M, Bixler EO. Insomnia with objective short sleep duration is associated with type 2 diabetes: a population-based study. Diabetes Care 2009;32(11):1980-5. http://dx.doi.org/10.2337/dc09-0284

9. al'Absi M, Arnett DK. Adrenocortical responses to psychological stress and risk for hypertension. Biomed Pharmacother. 2000;54(5):234-44. http://dx.doi.org/10.1016/S0753-3322(00)80065-7

10. Rosmond R, Björntorp P. The hypothalamic-pituitary-adrenal axis activity as a predictor of cardiovascular disease, type 2 diabetes and stroke.J Intern Med. 2000;247(2):188-97. http://dx.doi.org/10.1046/ j.1365-2796.2000.00603.x

11. Vgontzas AN, Bixler EO, Lin HM, Prolo P, Mastorakos G, Vela-Bueno A et al. Chronic insomnia is associated with nyctohemeral activation of the hypothalamic-pituitary-adrenal axis: clinical implications. J Clin Endocrinol Metab. 2001;86(8):3787-94. http://dx.doi.org/10.1210/ jcem.86.8.7778

12. Rodenbeck A, Huether G, Rüther E, Hajak G. Interactions between evening and nocturnal cortisol secretion and sleep parameters in patients with severe chronic primary insomnia. Neurosci Lett. 2002;324(2):159-63. http://dx.doi.org/10.1016/S0304-3940(02)00192-1

13. Riemann D, Klein T, Rodenbeck A, Feige B, Horny A, Hummel $R$ et al. Nocturnal cortisol and melatonin secretion in primary insomnia. Psychiatry Res. 2002;113(1-2):17-27. http://dx.doi.org/10.1016/S0165-1781(02)00249-4

14. American Psychiatric Association. Diagnostic and statistical manual of mental disorders. 5th ed. Arlington: American Psychiatric Association; 2013.

15. Buysse DJ, Reynolds CF 3rd, Monk TH, Berman SR, Kupfer DJ. The Pittsburgh Sleep Quality index: a new instrument for psychiatric practice and research. Psychiatry Res 1989;28(2):193-213. http://dx.doi.org/10.1016/0165-1781(89)90047-4
16. Rechtschaffen A, Kales A. Manual of standardized terminology, techniques, and scoring system for sleep stages of human subjects. Los Angeles: Brain Research Institute, UCLA; 1968.

17. Iber C, Ancoli-Israel S, Chesson AJ, Quan S. The AASM manual for the scoring of sleep and associated events: rules, terminology and technical specifications. Westchester: American Academy of Sleep Medicine; 2007.

18. Balbo M, Leproult R, Van Cauter E. Impact of sleep and its disturbances on hypothalamo-pituitary-adrenal axis activity. Int J Endocrinol. 2010;2010(2010):ID759234. http://dx.doi.org/10.1155/2010/759234

19. Bonnet MH, Arand DL. 24-Hour metabolic rate in insomniacs and matched normal sleepers. Sleep. 1995;18(7):581-8.

20. Vgontzas AN, Fernandez-Mendoza J, Liao D, Bixler EO. Insomnia with objective short sleep duration: the most biologically severe phenotype of the disorder. Sleep Med Rev. 2013;17(4):241-54. http://dx.doi.org/10.1016/j.smrv.2012.09.005

21. Rodenbeck A, Cohrs S, Jordan W, Huether G, Rüther E, Hajak G. The sleep-improving effects of doxepin are paralleled by a normalized plasma cortisol secretion in primary insomnia. A placebo-controlled, double-blind, randomized, cross-over study followed by an open treatment over 3 weeks. Psychopharmacology (Berl). 2003;170(4):423-8. http://dx.doi.org/10.1007/s00213-003-1565-0

22. Cappuccio FP, D’Elia L, Strazzullo P, Miller MA. Quantity and quality of sleep and incidence of type 2 diabetes: a systematic review and meta-analysis. Diabetes Care. 2010;33(2):414-20. http://dx.doi.org/10.2337/dc09-1124

23. Spiegel K, Leproult R, Van Cauter E. Impact of sleep debt on metabolic and endocrine function. Lancet. 1999;354(9188):1435-9. http://dx.doi.org/10.1016/S0140-6736(99)01376-8

24. Castro LS, Poyares D, Leger D, Bittencourt LR, Tufik S. Objective prevalence of insomnia in the São Paulo, Brazil, epidemiologic sleep study. Ann Neurol. 2013;74(4):537-46. http://dx.doi.org/10.1002/ana.23945

25. Jauch-Chara K, Oltmanns KM. Obesity: a neuropsychological disease? Systematic review and neuropsychological model. Prog Neurobiol. 2014;114:84-101. http://dx.doi.org/10.1016/j.pneurobio.2013.12.001

26. Keckeis M, Lattova Z, Maurovich-Horvat E, Beitinger PA, Birkmann S, Lauer CJ. Impaired glucose tolerance in sleep disorders. PLoS One. 2010;5(3):e9444. http://dx.doi.org/10.1371/journal.pone.0009444

27. Gottlieb DJ, Punjabi NM, Newman AB, Resnick HE, Redline S, Baldwin CM et al. Association of sleep time with diabetes mellitus and impaired glucose tolerance. Arch Intern Med. 2005;165(8): 863-7. http://dx.doi.org/10.1001/archinte.165.8.863

28. Punjabi NM, Shahar E, Redline S, Gottlieb DJ, Givelber R, Resnick HE. Sleep Heart Health Study Investigators. Sleep-disordered breathing, glucose intolerance, and insulin resistance: the Sleep Heart Health Study. Am J Epidemiol. 2004;160(6):521-30. http://dx.doi.org/10.1093/aje/kwh261

\section{ERRATUM}

In the article "Objective short sleep duration is associated with the activity of the hypothalamic-pituitary-adrenal axis in insomnia" published in the journal Arquivos de Neuro-Psiquiatria, 2015;73(6):516-519, in the page 516, for: "Gisele Passos" read "Giselle Soares Passos". 